\title{
Determinants of Expenditure on Health in Pakistan
}

\author{
REHANA SIDDIQUI, USMAN AFRIDI, and RASHIDA HAQ
}

An important component of human capital formation is improvements in the health status of the population. ${ }^{1}$ Improvements in the health status of a nation can lead to longer life expectancy, shift the labour supply curve outward, increase labour productivity, and increase the productivity of investment in other forms of human capital, particularly education.

Since health and the capacity to improve health are related to socio-economic conditions, it is important to analyse the impact of changes in these variables on the provision of health services. Due to the presence of externalities, market failures, and inability of a significant proportion of the population to pay, government intervention is required in the health sector. In this study, we shall analyse the changes in the provision of public health resources in Pakistan, in response to the changes in socio-economic factors.

Most empirical studies in this area have been cross-country studies. Fulop and Reinke (1983) emphasise that socio-economic factors affect the health status directly and indirectly. The indirect effect is through the changes in health resources in response to the changes in socio-economic factors. Kleiman's (1986) cross-country analysis shows that per capita national income, the ratio of government consumption expenditure to private consumption expenditure, and the measure of income inequality are important determinants of public expenditure on health. The study also shows that public and private expenditure on health are good if not a perfect substitute for each other.

Correa and Namkoong (1992) show that changes in health policies (or health resources), represented by changes in health personnel, infrastructure, and expenditure on health, are significantly influenced by Socio-economic and political conditions. Similarly, Hitiris and Posnett (1992); Gerdtham and Jonson (1992) and Murthy (1992) show that economic factors play an important role in determining the expenditure on health.

Rehana Siddiqui and Usman Afridi are both Research Economist and Rashida Haq is Staff Economist at the Pakistan Institute of Development Economics, Islamabad.

${ }^{1}$ Most popular indicators of health status are life-expectancy at birth, infant mortality rate, and disease-related death rates. 
In this study we examine the determinants of health resources for a single country, i.e., Pakistan. We analyse the effect of socio-economic factors on health resources which ultimately affect the health status. ${ }^{2}$ The socio-economic factors include gross national product-per capita, education, and urbanisation. Health resources include physicians, nurses, hospital beds and public health expenditure-per capita. However, we shall concentrate on public health expenditure-per capita as this variable is expected to represent the health policies pursued by the government more closely.

The main objective of this study is to test the hypothesis that changes in socioeconomic factors alone are sufficient to formulate policies regarding the provision of health resources necessary to meet the health requirements of Pakistan's growing population. The order of the study is as follows: Section 1 discusses health resources and socio-economic conditions in Pakistan. Section 2 deals with the model, methodology, and data. Section 3 is for the discussion of results. The conclusion and policy implications are reported in Section 4.

\section{HEALTH RESOURCES AND SOCIO-ECONOMIC CONDITIONS IN PAKISTAN}

In Pakistan, although the health status has improved significantly over time, yet it is still far below the international standards. The data shows that selected vital health indicators vary significantly in selected 11 Asian countries. ${ }^{3}$ If we rank these countries on the basis of life expectancy at birth, Pakistan is ranked 9th in the group of 11 Asian countries. Similarly, other indicators show that Pakistan has to work very hard to improve the health status of its population.

Being a developing country, Pakistan spends very little on the provision of health services. Although public health expenditure increased by 430 percent during 1970-78, the rate of change declined after that. The range of ratio of health expenditure to gross domestic product varied between $0.4-0.9$ percent during 1972-93.

How changes in health spending affect the health status of a nation is an important issue. Developing countries, where 78 percent of the world population lives, spend only 10 percent of the total world health expenditure. ${ }^{4}$ The shares of health expenditure in gross national product (GNP) are also significantly different across regions. In 1991, developing countries spent only 4.7 percent of their GNP on health, whereas the ratio was 9.2 percent for established market economies (EME). Furthermore, per capita health expenditure in Pakistan is only 1/10 of the health

${ }^{2}$ We are not analysing the impact of the changes in socio-economic conditions and the changes in health resources on the health status because consistent time series data for any indicator of the health status are not available.

${ }^{3}$ Table is available from the authors.

${ }^{4}$ The relevant table is available from authors. 
expenditure in Sub-Saharan Africa (SSA), the poorest region in the world. These differences in health expenditure make it critical to understand the impact of government health policies.

The health indicators show that doctors, nurses, and the number of hospital beds have increased very sharply in Pakistan. ${ }^{5}$ However, this increase is affected by the rapid population growth rate. For example, the growth rate of hospital beds is almost equal to the population growth rate, which shows that the availability of hospital beds per (000) person declined at a slow rate of 0.89 percent during 1973-93. However, the growth rate of health personnel, i.e., doctors, nurses, and midwives, was quite significant. Similarly, nominal health expenditure grew very rapidly during 1973-94, but real development expenditure on health did not change, and almost 50 percent of nominal nondevelopment expenditure was absorbed by higher prices.

In spite of rapid growth in health personnel, access to health facilities was limited particularly due to rising cost of medical services and medicines, unequal distribution of health facilities between urban/rural areas, and inefficient utilisation of available health resources. For example, doctor's consulting fees, on average, increased by 12.32 percent per annum during 1973-93. Furthermore, despite government announcements to control the prices of medicines (particularly of life-saving drugs), the prices have increased by more than 100 percent during the recent years.

In many cases, the infrastructure was available but could not be fully utilised because of the shortage of funds for personnel, medicines, and maintenance. Mubarak (1990) reports that negligence of health personnel also results in lower utilisation of health facilities. According to his study, health providers are not available to patients for 60 percent of the official working hours and 90 percent of the total time. About 33 percent of rural health facilities do not open on time in the morning. ${ }^{6}$ Furthermore, the efforts to provide incentives to doctors to work in rural areas have resulted in private practice in areas of their choice, usually urban. According to the Annual Report of the Director General Health (ARDGA-1990-91), the number of private practitioners (males) increased at a growth rate of 9.2 percent per annum during 1978-90. This rapid growth in private practitioners, with rapid rise in doctor's fees and rising cost of medicine, has worsened the quality of health services available in rural areas. Furthermore, despite rapid growth in the number of health personnel, ARDGA-1990-91 reports that almost 50 percent of the vacancies are not filled. This is another indicator of the poor quality of health service available in public hospitals. Understaffing and lack of other facilities affects the efficiency of the existing staff.

${ }^{5}$ Relevant data are available from the authors.

${ }^{6}$ Mubarak (1990) reports that “...wrong selection of sites for health units, non-availability of medicines or staff, inconveniences like long distance, wrong working hours, long waiting times, and inadequate services and attitude...” are the major causes of lower utilisation of government health facilities. 
Concluding this section, we can say that the existing health facilities are grossly inefficient and underutilised. In order to improve the quantity and quality of health resources, we need to do the following: increase the number of health facilities; allocate sufficient resources to make them function properly; effective supervision; provision of sufficient incentives for the health personnel; and active involvement of the community are important factors. These steps are required to achieve a higher and efficient level of utilisation.

\section{MODEL, METHODOLOGY, AND DATA}

\section{(a) Model and Methodology}

Our objective is to analyse the basic relationship, at the national level, between socio-economic factors and health resources in a developing country like Pakistan. ${ }^{7}$ The basic hypothesis is that favourable socio-economic conditions, particularly changes in gross domestic product per capita-GNPP, and education-E affect resource allocation for improving the health status of a nation. ${ }^{8}$ Alternatively, we shall test whether changes in socio-economic conditions are sufficient to formulate desired health policies. Since political conditions are expected to play an important role, the effect on health policies may be multidimensional. Empirical evidence, based on cross-country data, presented in Correa and Namkoong (1992); Hitiris, and Posnett (1992); Gerdtham and Jonson (1992) and Fulop and Reinke (1983), do not give us any conclusive evidence. The influence of the socio-economic factor $(x)$ and political conditions $(D)$ on health resources $(H R)$ is characterised as:

$$
H R=f(X, D) \quad \ldots \quad \ldots \quad \ldots \quad \ldots \quad \ldots \quad \ldots
$$

Fulop and Reinke (1983) postulate that socio-economic factors affect $H R$ and both $X$ and $H R$ in turn affect the health status of a nation. For the present study, we have ignored the second part of the relationship due to non-availability of appropriate data. Inclusion of ' $\mathrm{D}$ ' in Equation (1) adds one more dimension in the first part of the relationship. Following Correan and Namkoong, we can postulate:

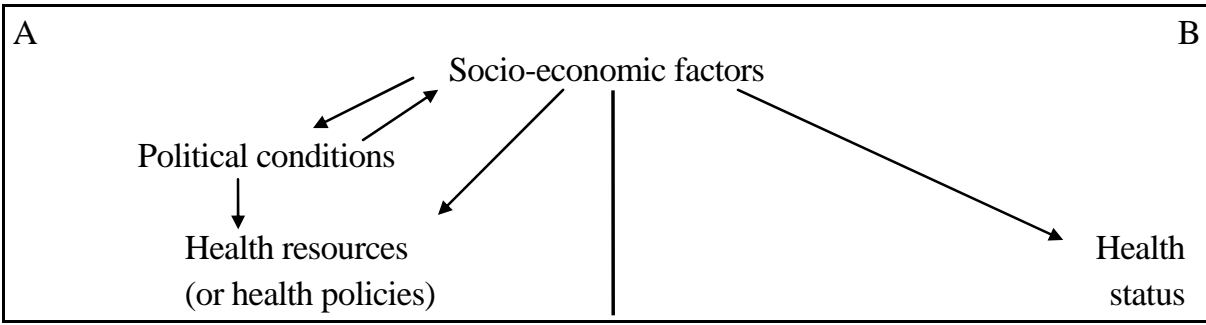

\footnotetext{
${ }^{7}$ Health resources are directly related to health policies of the government. Therefore, changes in health resources are expected to represent changes in health policies.

${ }^{8}$ Changes in health status can be represented either by changes in life expectancy at birth or by changes in infant mortality rate.
} 
In this study, only part A of the box is examined. Since health policies are complex and multi-dimensional, it is appropriate to analyse the following variables as health policy indicators: number of doctors per (000) persons, nurses per (000) persons, hospital beds per (000) persons, and public health expenditure per person. These variables are taken as indicators of government's health policy as Pakistan spends a significant amount of resources to educate and train doctors and nurses, and to supply the infrastructure like hospitals and beds. Health expenditure is expected to be the most significant indicator of health policy or health resources. Health expenditure is divided between development and non-development expenditure. We shall analyse these two components separately, as the impact of the two components of health expenditure on health status may vary. The impact of development expenditure may be realised after time lag where as the impact of non-development expenditure may be realised during the same time-period. According to World Bank (1993), this indicator of health resources is important as it can help the governments to increase welfare through better health outcomes, greater equity, and more consumer satisfaction at lower total cost than would occur in the absence of public action.

The following socio-economic variables are expected to be significant determinants of health resources.

Gross Domestic Product-per capita (GDPP) is expected to influence health policies positively as it is expected to affect the availability of private and public resources for health. The effect of rapid urbanisation $(u)$ on health resources may be positive or negative as rapid urbanisation may increase the demand for health facilities but it can also lead to deterioration of existing health facilities if they do not increase with the increase in urban population.

The effect of the rise in educated population $(E)$ is expected to lead to better personal care and to better awareness of the demand for more and better health facilities. The inclusion of private health expenditure as a determinant of public non- development health expenditure will help us test whether private expenditure is substituting or complementing public health expenditure.

In Pakistan, the political philosophy has changed significantly during 1974-93. Since political philosophy is expected to affect government's decision and their ability to translate people's demand and need in policy, we include variable $D$ in Equation (1). $D$ $=0$ for the seventies when nationalisation policies of the government may have affected the resource availability for health. $D=1$ for 1980s and 1990s when the nationalisation policy was reversed.

Government's attitude as a provider of public utilities may also affect public health expenditure. The ratio of government consumption to private consumption is used as a proxy for government attitude.

After including these variables, Equation (1) can be written as:

$\begin{array}{llllll}H R_{i} & =f(G D P P, U, E, D) & \ldots & \ldots & \ldots & \ldots\end{array}$ 
where

$H R_{i}=$ ith health resource variable.

In order to estimate this relationship, we can either conduct Discriminant Analysis, adopted by Correa and Namkoong, or we can conduct multivariate regression analysis for each variable representing health resources. We shall adopt the second approach, as it is direct and simple, for future policy recommendations.

\section{(b) Data}

The time-period for the analysis is 1974-93, and the main data source is Government of Pakistan (1994). GDPP and health expenditure data are expressed in constant prices after adjusting the expenditure for changes in prices (1980-81 is the base year). The data series on private health expenditure are constructed on the basis of the information available from Government of Pakistan (Various Issues). The question of the quality of data exists, and as Mubarak (1990) concludes, the health data are very unreliable and we need to develop "..... an effective and reliable National Statistics Information Collection System for better management of health services may simultaneously be developed and introduced along with the National Health Delivery System”.

\section{RESULTS}

Table 1 reports the determinants of physical health resources. The table shows that socio-economic factors play an important role as determinants of the availability of health-related personnel and infrastructure. The table shows that doctors per (000) person increase significantly in response to the changes in GDPP. The changes in GDPP also significantly affect the availability of nurses per (000) persons and also of hospital beds. Similarly, urbanisation is an important determinant of the availability of health personnel and infrastructure. However, the inclusion of the education variable affects the significance of the other coefficients, particularly the coefficient of GDPP. This shows that education and GDPP are strongly collinear. The coefficient of $D$ shows that the availability of health personnel and infrastructure declined during the post- 1978 period. However, the coefficient is statistically significant for doctors only. The results confirm our assertions that the availability of health personnel and infrastructure has an urban bias and the socio-economic factors affect health resources significantly.

The results reported in Table 2 show that GDPP is a significant determinant of non-development expenditure on health. Estimated equation (4) for non-development expenditure shows that urbanisation has a negative and statistically significant effect. The effect of education is surprisingly negative. The coefficient of CG/GP shows, as expected, that as more resources are consumed by the government, the expenditure on 
Table 1 
Table 2 
health rises. The results also show that in the post-1978 period, non-development expenditure on health was significantly and positively different from that in the pre-1978 period. This result is different from the result for health personnel and health infrastructure. This is a surprising result and needs further elaboration. Another important point to note is that government non-development expenditure on health and private expenditure on health seem to be complementary. This result contradicts the finding of Kleimen (1986), based on cross-country data, that public and private expenditures on health are substitutes.

Development expenditure on health is responsive to the changes in CG/CP only. Change in political regimes has also significantly and positively affected development expenditure. However, as expected, other socio-economic factors are not statistically significant. This result indicates that the aggregation of non-development and development may lead to misleading conclusions regarding the significance of determinants.

Our results support Fulop and Reinke (1983); Kleiman (1986) and Correa and Namkoong's (1992) assertion that socio-economic factors and political changes play an important role in determining public expenditure on health. However, our results indicate that the conclusions based on cross-country evidence may differ from the results for a single country. Furthermore, the aggregation of non-development and development expenditure may give us misleading results. Therefore, we can conclude that health policies are not only affected by political changes but that socio-economic factors also play an important role. Thus, it is desirable to analyse this aspect at a disaggregated level.

\section{CONCLUSIONS}

This study shows that socio-economic factors and political conditions play an important role in determining health resources in Pakistan. The evidence shows that although the availability of health resources like doctors and nurses is increasing in Pakistan, yet their utilisation and distribution remain major problems. Furthermore, as Zaidi (1988) shows, the analysis should be done at a disaggregated level if we want to formulate effective programmes for the provision of health cover to the entire population by the year 2000 . We intend to analyse these issues in the near future.

\section{REFERENCES}

Correa, H., and K. Namkoong (1992) Determinants and Effects of Health Policy. Journal of Policy Modelling 14:1 41-63.

Fulop, T., and W. A. Reinke (1983) Health Manpower in Relation to Socioeconomic Development and Health Status. In D. Salkener, I, Sirageldin and Sorkin (eds) Research in Human Capital and Development. 3: 329-352. 
Gerdtham. Ulf-G., and B. Jonson (1992) International Comparisons of Health Care Expenditure-Conversion Factor Instability, Heteroscedasticity, Outliers and Robust Estimators. Journal of Health Economics 11: 189-197.

Hitiris, T., and J. Posnett (1992) The Determinants and Effects of Health Expenditure in Developed Countries. Journal of Health Economics 11: 173-181.

Kleiman, E. (1986) The Determinants of National Outlay on Health. In The Economics of Health and Medical Care. IEA Conference, Tokyo, Vol. 40, M. Stockton Press, New York.

Meier, G. M. (1984) Leading Issues in Economic Development. New York: Oxford University Press.

Mubarak, M. M. (1990) Health Coverage in Pakistan-An Evaluation for Future Strategy. Rawalpindi: The Army Press.

Murthy, V. N. R. (1992) Conversion Factor Instability in International Comparisons of Health Care Expenditure: Some Econometric Comments. Journal of Health Economics 11: 183-187.

Pakistan, Government of (1994) Pakistan Economic Survey 1993-94. Islamabad: Finance Division.

Pakistan, Government of (Various Issues) Household Income and Expenditure Survey. Islamabad: Finance Division.

World Bank (1993) World Development Report 1993. Washington, D. C.: World Bank.

Zaidi, S. A. (1988) The Political Economy of Health Care in Pakistan. Lahore: Vanguard Books (Pvt.) Ltd. 